\section{IJ§ER}

ISSN: 2149-5939
International Journal of Social Sciences and Education Research

Online, http://dergipark.gov.tr/ijsser

Volume: 3(1), 2017

\title{
The effect of L2 English proficiency on request, advice and apology of L1 Turkish-L2 English learners
}

\author{
Gülümser Efeoğlu Şentürk ${ }^{1}$
}

\begin{abstract}
Received Date: 09 / 09 / 2016
Accepted Date: $25 / 12$ / 2016

Abstract

Since Bachman and Palmer (1996) and Canale and Swain (1980) introduction of "pragmatic competence" in the field of L2 acquisition, its relation to other factors interacting with it has attracted attention of a number of researchers. The present study aims to explore the intertangled relation between two competences (namely pragmatic and structural) in three distinct areas such as request, advice and apology in L2 context. For the purposes of the current study, two data collection tools are employed. The first one is English Language Proficiency Test while the second is a discourse completion task. The latter consists of three subsections and each subsection involves four cases each of which targets exchanges between interlocutors with equal statues. The findings suggest that even though two distinct proficiency groups differ for some cases like requests, L2 proficiency is not a comprehensive indicator of L2 pragmatic competence development on its own.
\end{abstract}

Keywords: Pragmatic competence, L2 proficiency, request, apology, advice

\section{Introduction}

In every attempt to mean something we aim to be understood and to convey our message to the other party. Thus, for that very specific purpose, we make use of a number of linguistic and nonlinguistic sources. To start with, in accordance with our message, we decide on lexical items and appropriate structures that would serve for the purposes of our message perfectly. There is a sort of hidden force which is also called "illocutionary act" and defined as "the primary act that the speaker intends to perform" by Holtgraves (2008, p.362). Thus, this force is the reason that makes people communicate, which aroused curiosity among many researchers such as Austin who is the first one provided detailed description of the speech acts (1962) and Searle who categorized them as assertives, directives, commissives, expressives and declarations (1975). Moreover, it is possible to communicate the same message through a number of structures varying in their degree of appropriateness, linguistic complexity, degree of directness, etc.

In line with the role of speech acts in first language, pragmatic competence development in L2 context is much more intriguing as there are a number of factors interacting with that process. The current study aims to find out the relationship between language proficiency of L2 learners and their employment of particular speech acts.

\section{Literature review}

As stated before, there is an immense amount of research on the description and the categorization of speech acts (Bardovi-Harlig and Hartford, 1990; Hinkel, 1997; Martinez-Flor, 2005;

${ }^{1}$ gulumserefeoglu@gmail.com 
Efeoğlu Şentürk, G. (2017). The effect of L2 English proficiency on request, advice and apology of L1 TurkishL2 English learners. International Journal of Social Sciences and Education Research, 3(1), 297-306.

Sbisa, 2002; among many others). These are sound attempts to highlight the fine distinctions between speech acts.

One of the main distinction between speech acts lies on the availability of the verb purposed with the proposition of the verb. Mainly, some speech acts involves the direct use of verbs for specific acts. For instance, the main verb in a sentence like "I promise to come back." explicitly refers to the speech act itself. So, there is no need for the interlocutor to go beyond the surface representation which signals the promising of the speaker directly. On the other hand, in sentences with no such verb, interlocutors have to derive those interpretations on their own solely based on the context. Thus, the latter is defined as implicit speech acts by Holtgraves (2007).

In addition to that, the categorization has been made on the type of action required from the hearer such as requests, suggestions, advice, complaints, apologies, and so on. There are a number of studies focusing on one or more than one aspects of these actions in the pragmatics literature.

When the focus shifts from L1 to L2, detailed analysis of the speech acts becomes more challenging. More explicitly, since it is not quite straightforward to provide the precise description of L2 acquisition as a construct referring to its all dimensions early studies focused on the structural aspect more, which yielded a number of studies on the interlanguage grammar. Meanwhile, appropriateness of the grammatically accurate structures is neglected. However; in line with the shift in the construct of L2 acquisition, the focus has also shifted to the pragmatic aspect of this process from more structuralist one. Indeed, this change reflects the change in the perception of what it means to know a foreign language. In the past, the structuralist view of language which highlighted the isolated linguistic descriptions had dominated the teaching philosophy. However, with the introduction of communicative competence into the literature by researchers such as Bachman and Palmer (1996) and Canale and Swain (1980), it has been believed that grammatical aspect is necessary but not the sufficient basis for "knowing a second/foreign language". Thus, there is an increasing interest in pragmatic development of L2 learners.

Some of these studies highlighting the L2 pragmatic competence focused on the comparison of L1 and L2 processing of speech acts. For instance, Taguchi (2002) compared L1 and L2 in terms of comprehension of different types of indirect meanings in speech acts. It was found out that although less proficient learners are less confident in their explanations, there is no significant difference between L1 and L2 group in terms of their making sense of different types of indirect speech acts. In addition to this, Taguchi (2005) investigated L1 and L2 learners' reactions to more and less conventional indirect speech acts. By more conventional, she meant those frozen or formulaic structures such as "Would you mind if I X?". At the end of the study, it was found out that L1 users showed no sign of difference between more and less conventional indirect speech acts whereas L2 users relied more on the more conventional structures (Taguchi, 2005). It has been claimed that this tendency is related to L2 learners' feeling more secure with the structures that they know very well instead of being related to their overall L2 proficiency (Taguchi, 2005). In brief, when L1 and L2 pragmatic competence is compared, it is not as straightforward as in many other aspects in which there is usually a high correlation between overall language proficiency and the performance on that specific linguistic aspect.

Another line of research on pragmatic competence of L2 learners have been shaped by the investigation of different speech acts. To illustrate, Bardovi-Harlig and Dornyei (1998) studied on the request, apology, suggestion, and refusal uses of ESL, EFL and native speakers in terms 
Efeoğlu Şentürk, G. (2017). The effect of L2 English proficiency on request, advice and apology of L1 Turkish-

L2 English learners.. International Journal of Social Sciences and Education Research, 3(1), 297-306.

of both pragmatic and structural development. Similarly, the range of requesting strategies used by Japanese native speakers of EFL learners has been extensively studied by Hill (1997) and Takahashi (1996). Furthermore, following the same fashion, there are studies conducted with a number of participants from dissimilar native backgrounds. Some of these are Scarcella's study (1979) with L1 Arabic- L2 English learners, Olshtain and Blum-Kulka's study (1985) with L1 Hebrew, Trosborg's study (1987) with L1 Danish-L2 English, Rose's study (1998) with L1 Cantonese- L2 English among many others. There is diversity in terms of the focus of these studies, yet still they all contribute to pragmatic development in L2 from a different perspective. The diversity is also evident with studies combining different aspects of language learning into L2 pragmatics. For instance, Takahashi (2005) investigates the entangled relationship between motivation and proficiency and "pragmalinguistic" awareness. The results reveal that while motivation has an observable effect on it no such relation has been confirmed for proficiency. Similarly, the current study is predicted to shed light on the manifold relation between L2 proficiency and pragmatic competence in three distinct types of speech acts.

\section{The present study}

The current study aims to account for the pragmatic development (particularly advice, request, and apology) of Turkish native speakers with varying degrees of English proficiency. As there is no consensus on the relation between overall language proficiency and learners' pragmatic competence, this study is believed to contribute to our understanding of these concepts. As for these very specific purposes of this study, there are two questions introduced below.

- To what extend are FLED students' speech act preferences different from each other?

- Are there any observable relations between language proficiency and participants'pragmatic competence development?

As it is pointed out with the questions above, the focus is on the interaction between L2 proficiency level of participants and L2 pragmatic competence which is basically the comparison of two different groups in terms of their responces in DCTs (Discourse Completion Tasks).

\section{Methodology}

\subsection{Participants}

Participants are 40 (20 prep and 20 freshmen) participants all of whom study foreign language teaching at Y1ldız Technical University.

Table 1. Participants

\begin{tabular}{|c|c|c|c|}
\hline & $\mathbf{N}$ & Gender & Mean Age \\
\hline High Proficiency Group & 20 & F: 15 & 19,95 \\
\hline Low Proficiency Group & 20 & $\begin{array}{lc}\text { F: } & 15 \\
\text { M: } & 5\end{array}$ & 18,68 \\
\hline
\end{tabular}

As these students are accepted to department, a proficiency test (English Language Proficiency Test) is administered in order to determine the proficiency levels of these students. Thus, all these students took English proficiency test assessing their linguistic and vocabulary knowledge as well as their reading, writing, listening and speaking skills. The test results yield two proficiency groups as High Proficiency (HP) group and Low Proficiency (LP) group. 
Efeoğlu Şentürk, G. (2017). The effect of L2 English proficiency on request, advice and apology of L1 TurkishL2 English learners. International Journal of Social Sciences and Education Research, 3(1), 297-306.

\subsection{Instruments}

As stated above, the English Language Proficiency (henceforth ELP) test has been considered to be the indicator of their English proficiency. In addition to it, DCT was devised in order to find answers to the questions above with two specific headings. In the first part, there were three cases all of which require the reader to give some advice in accordance with the imaginary cases. In the second section, there were three different cases for requesting. In the third one, three cases asking for the production of apology were included.

Moreover, all these cases are highly restricted to academic context and the most frequent type of relation is English native speaker friend talking a Turkish friend at a university context. In order not to bias results with the degree of politeness resulted from the power relations between the speaker and hearer, the context has been very restricted and limited to only a university context.

\subsection{Procedure}

Initially, ELP test has been administered. Those who score 60 and above are categorized as HP group while the rest being LP group. Subsequently, DCT tasks were designed by the researcher and piloted with a native speaker of English in order to check the comprehensibility of the task. Afterwards, DCTs were also administered to both groups on a voluntary basis. DCTs were conducted with both groups at different times, which is still in the same week.

\subsection{Data analysis}

The primary data from ELP test results were analyzed quantitatively by dividing participants into two groups. Data gathered from DCTs were analyzed qualitatively. In order for that, there appeared the need to base the categorization and coding of data on reliable and valid frameworks. The Cross-Cultural Speech Act Realization Project (CCSARP) (Blum-Kulka et al. 1989) analyzed requests and apologies in eight different languages by using the same coding framework. Thus, this framework has been preferred over the others. In this framework there are two categories: direct and indirect (conventional indirect, and non conventional indirect). The following categorization has been used for coding the data.

I. Direct Expressions

1. Imperatives e.g., Please lend me a pen.

2. Performatives e.g., I'm asking you to lend me a pen.

3. Implicit performatives e.g., I want to ask you to lend me a pen.

4. Obligation Statements e.g., You should lend me a pen.

5. Want Statements e.g., I want you to lend me a pen.

13. Ability/ Can Do Statements e.g. You can buy a car.

14. Possibility: May-Might Statements e.g.;

II. Indirect Expressions

II.A. Conventional indirect

6. Preparatory questions e.g., Could you lend me a pen? 
Efeoğlu Şentürk, G. (2017). The effect of L2 English proficiency on request, advice and apology of L1 TurkishL2 English learners.. International Journal of Social Sciences and Education Research, 3(1), 297-306.

7. Suggestions e.g., How about lending me a pen?

8. Permissions e.g., May I borrow a pen?

9. Mitigated Preparatory e.g., I'm wondering if you could lend me a pen.

10. Mitigated Wants e.g., I'd appreciate it if you could lend me a pen.

15. Would you mind

II.B. Non-conventional indirect

11. Strong hint e.g., My pen just quit. I need a pen.

12. Mild hint e.g., Can you guess what I want?

(Adapted from Taguchi, 2006, p. 521)

\section{Results}

Advice: As for advice section, there were three different cases: In the first one, participants were asked to give some advice as for the things to do in İstanbul. In the second one, they were required to give advice for an American exchange student who has difficulty in learning Turkish. As for the last case, they were asked to give advice to an exchange student who wishes to buy a car in Turkey. The table below indicates the responses gathered from the participants.

Table 2. Results for advice

\begin{tabular}{clll}
\multicolumn{1}{c}{ Group } & \multicolumn{1}{c}{$\mathbf{1}^{\text {st }}$} & \multicolumn{1}{c}{$\mathbf{2}^{\text {nd }}$} & \multicolumn{1}{c}{$\mathbf{3}^{\text {rd }}$} \\
\hline High Proficiency Group & D: imperative & D: obligation & D: ability \\
\hline Low Proficiency Group & D: ability & D: obligation & D: imperative \\
\hline
\end{tabular}

As it is evident from the table, both groups of participants preferred to use direct responses instead of indirect ones. In terms of the direct uses, there are three frequent patterns: The first one is related to the use of advice as the imperative verb in their responses for HP group, which is also surprising as there are finer ways of giving advice. However, since the interaction was set as between friends, they could have felt more comfortable in using imperatives. Lastly, it may also be related to the formation of imperatives, which is relatively straightforward when compared to some other forms. The second common response that is valid for both HP and LP groups was the direct uses of obligation referring to "should" use, which is associated with strong suggestion. Being the third most frequent response for the HP group and the first for the LP group "can" was marked as direct use of ability and is also an acceptable way of giving advice in English. In brief, it is evident that both HP and LP participants prefer the direct uses instead of indirect ones while giving advice to their friends.

Upon comparing two proficiency groups, it is difficult to observe any significant difference between these two. Similar to LP group, HP participants preferred to give advice by using direct speech acts instead of indirect one. Furthermore, in direct ones preferences were the same: imperative, obligation and ability. However, they differ in their degree of reliance on imperatives and ability. To illustrate, LP participants employed ability more frequently while it is the third in the rank for HP participants. On the other hand, there is overlap in terms of their reliance on direct speech acts: In all conditions, there are only two instances of indirect use in both groups, which proves that these particular prompts initiate direct use of specific type of speech acts irrespective of participants' proficiency. 
Efeoğlu Şentürk, G. (2017). The effect of L2 English proficiency on request, advice and apology of L1 TurkishL2 English learners. International Journal of Social Sciences and Education Research, 3(1), 297-306.

Requests : As for the request section there were again three cases: in the first one, participants were asked to communicate with an exchange student to invite him/her to their birthday party. In the second one, they are required to ask for help for their computer broken-down from an exchange student who is good at solving technical problems. In the last one, there was a bookseller from whom they are expected to get some help in finding a particular book in a book store. The table below indicates the results for both HP and LP groups.

Table-3. Results for request

\begin{tabular}{llll}
\hline Group & $\mathbf{1}^{\text {st }}$ & $\mathbf{2}^{\text {nd }}$ & $\mathbf{3}^{\text {rd }}$ \\
\hline High Proficiency Group & I: would & I: Strong hint & D: imperative \\
& I: Preparatory Question & D: want & \\
\hline Low Proficiency Group & D: ability & I: Strong hint & I: Preparatory Question / \\
& & & D: want \\
\hline
\end{tabular}

With the table above, it is obvious that there is a clear-cut distinction between HP and LP participants' request formation. Although there is almost an even distribution of direct and indirect tools, the type of tool does differ to a great extent. Following the same line of thought, LP group seems to rely more on the less complex and more direct tools such as can and want. However, HP group employs a variety of tools which differ in terms of structural complexity.

Contrary to the findings for advice, patters in request indicate weak correlation between two groups although there is no unified picture of speech act use. Both direct and indirect uses are available. However, different from LP participants, the use of would is more frequent in HP group. In addition to that "can" use in requests is only limited to LP group while requesting. Still, the second most frequently employed tool for both groups is just the same: Indirect: strong hint. An example for such a case is presented in the following example:

The prompt case: Your computer has broken down and you know that one of your friends, John is highly familiar with hardware and software of computers. When you call him for help, what would you say?

LP4: "John, I have trouble with my computer, I think it has broken, I need someone who is familiar such things as you to fix it."

As it is evident with the example, instead of asking a direct question for help, the participant describes the reasoning behind his/her request and implies that $\mathrm{s} /$ he needs John's help. The participant may find it less face threatening since it is highly indirect. The underlying meaning that is wished to be conveyed to the other party may be the following: Anybody with these qualifications will be fine for me. You seem to the perfect person who can handle with it since you are one of these people.

In short, even though the general layout is highly dissimilar for two sets of data, closer and detailed analysis reveals some similarities between these two groups as it is the case in their indirect: strong hint preferences.

Apology: As for apology, there are three different cases. In the first one, participants were asked to apologize for being late to the exam. In the second case, participants were asked to apologize from an exchange student for losing her book. The last one is related to apologizing from an American instructor because the participant spills some of the sauce over him. As it is clear with items, each and every one of them sets distinct settings of interaction. 
Efeoğlu Şentürk, G. (2017). The effect of L2 English proficiency on request, advice and apology of L1 Turkish-

L2 English learners.. International Journal of Social Sciences and Education Research, 3(1), 297-306.

Table 4. Results for apology

\begin{tabular}{llll}
\hline Group & $\mathbf{1}^{\text {st }}$ & $\mathbf{2}^{\text {nd }}$ & $\mathbf{3}^{\text {rd }}$ \\
\hline High Proficiency Group & D: sorry & $\begin{array}{l}\text { D: apologize } \\
\text { I: Responsibility }\end{array}$ & I: Repair \\
\hline Low Proficiency Group & D: sorry & D: excuse & I: explanation \\
\hline
\end{tabular}

As it has been indicated by the table above, both LP and HP participants preferred to apologize by saying "I am so sorry" in almost all of the instances when they were asked to react. Thus, this is a reflection of their acquisition of appropriateness. They indicated that they learned to start by showing that they are sorry which subsequently followed by the explanations related to the problem. In short, it is quite straightforward that they assumed "I am so sorry" sort of answer as the default form in answering to apologies.

When compared, both HP and LP participants chose the direct way of apologizing saying that you are sorry. Nonetheless, two groups significantly differed in their employment of the second and third most frequently used tools. As for HP group, direct use of apology as in "I apologize..." and indirect uses such as responsibility and repair are significant tools. Nevertheless, LP groups preferred providing excuses directly as in "Excuse me" and explanations that would function as an implicit tool that would reduce the burden on the speaker. The following examples illustrate a case of responsibility and repair by HP participant and explanation by LP participant respectively.

The prompt case: You borrow a book from your friend Mary, an exchange student from Britain. When your friend wants it back, you could not find it at home and you are very sorry. What would you say to your friend when s/he asks you about the book?

HP12: Oh Mary I am afraid but I couldn't find your book at home. But, I will buy you a new one and make up my fault.

The prompt case: You are supposed to take a very important exam early in the morning; but due to traffic jam you are late. What would you say when to arrive at the building?

LP11: I didn't mean to be late but because of the traffic I couldn't manage to be here on time.

However, the formation of such an implicature is more challenging than simply saying that you are sorry. As HP participants are more proficient in English presumably, they are capable of employing more examples of indirect speech acts particularly responsibility and repair type.

\section{Discussion}

The results of the study reveal answers for the questions posed at the initial stages. It is obvious that L2 proficiency does not account for the diversity in participants' reactions for all cases. More explicitly, each speech act has its own specific tools and for some cases such as advice and partly for apology participants' reactions were just the same irrespective of their L2 proficiency.

Going back to the first research question investigating any difference between groups; it has made clearer that there are some differences. This question has been extensively discussed in the results section saying that there are a great number of overlaps between two groups along with the distinctions. Each speech act prompt directs its reader to a particular set of speech acts. Participants' responses differed based on their perceptions, English language proficiency and their pragmatic competence. As for advices, most of the participants in both groups preferred direct use of ability and imperative sentence, which is highly influenced by the relationship set between 
Efeoğlu Şentürk, G. (2017). The effect of L2 English proficiency on request, advice and apology of L1 TurkishL2 English learners. International Journal of Social Sciences and Education Research, 3(1), 297-306.

speakers. Both groups employing highly similar structures does not mean that the L2 proficiency is not a good sign of L2 pragmatic competence. Bardovi-Harlig and Griffin (2005) suggests that some threshold level may be enough for L2 learners to use speech act appropriately in some contexts.

Using expected speech acts, semantic formulas or content can go a long way pragmatically while grammar is still developing (Bardovi-Harlig and Griffin, 2005, p. 411).

In terms of requests, both direct and indirect speech acts were used by both groups and the distribution has shown some variation. This is the only category that two groups diverged mostly. In particular, the use of "can" which was marked by D: ability code was only evident in LP group signaling a proficiency difference between two groups. In addition to this, HP group's choice of imperatives as the third most frequent tool is quite counter-intuitive as they are predicted to use more complex tools. However, the reason for them to prefer relatively less complicated tool may reside in the type of relation set between interlocutors. Since participants were instructed to imagine a conversation between people with equal statues, they might have felt more relaxed and found it appropriate to use imperatives for requesting.

As for apology, the findings were quite straightforward. Almost everybody in each group used "I'm sorry" which is an indirect way when compared to direct performative act such as I apologize..... Moreover, it has no roots in L1. If it were L1 translation, they we would expect participants to produce more "I apologize..." sort of sentences because in Turkish it is said "ozur dilerim" (I apologize...) more often than "uzgunum" (I am sorry) on order to apologize. In conclusion, it is significant to bear characteristics of each speech act in mind while at the same time being aware of the fact that there may well be discrepancies resulted from proficiency level, different L1 backgrounds, and individual differences, etc.

The second research question of the study on any observable relations between language proficiency and participants' pragmatic competence development has already been discussed in the previous sections stating that some of the dissimilarities between HP and LP groups may stem from the latter's being less competent in L2 English. As Trosborg (1987) states in the following quotation, structural competence is highly related to pragmatic competence.

The low number of explanations used by learners is likely outcome of insufficient linguistic knowledge. In order to provide a convincing explanation or give an adequate account you need the relevant linguistic means (Trosborg, 1987, p. 165).

Furthermore; when we look at the overall picture, preferences of HP participants varied more compared to LP participants, which may be attributed to HP's being more proficient enable them to use a number of structures.

\section{Conclusion}

In brief, this study has provided a different perspective to the ongoing entangled relation between pragmatic and structural competences in L2 context. For the time being, it was made clearer that there are distinctions between types of different speech acts, which would yield a difference in participants' reactions. On the other hand, the degree and the type of similarities evident in the data demonstrate that in addition to L2 proficiency some other factors influence L2 learners' decision of what is appropriate in a particular context. More explicitly, the proficiency level of participants in the target language is a significant indicator of their pragmatic competence as it has 
Efeoğlu Şentürk, G. (2017). The effect of L2 English proficiency on request, advice and apology of L1 TurkishL2 English learners.. International Journal of Social Sciences and Education Research, 3(1), 297-306.

been shown by the discrepancy between HP and LP participants although it not a "sufficient" condition on its own. In addition to that, some L1 features are evident in participants' L2 productions. In short, the current study with its specific objectives highlighted proficiency and pragmatics interaction in L2 context referring to three distinct types of speech acts.

However, this study is not without its limitations. Unlike some studies in the literature, the proficiency test utilized in this study is not a standardized test, which may result in some deficits in grouping the participants. But still, even if it is not standardized, all four skills are tested and evaluated by two raters in writing and speaking. Thus, it may be regarded as relatively reliable tool of L2 English proficiency. Apart from this, DCTs in this study assume equal statues between interlocutors, which restricts the scope of the study. Further studies may involve some more cases that would tap different type of statues relations for participants. Lastly, this study could have provided more solid results if the same cases used in DCTs had been tested in participants' L1 as well because $\mathrm{L} 1 \mathrm{effect}$ is one of the most prominent factors that influence L2 pragmatic competence. All in all, with the current study it is obvious that L2 proficiency is a significant determinant of L2 pragmatic competence while the degree of interaction is affected by the targeted speech act and the prescribed context.

\section{References}

Bachman, L. F., \& Palmer, A. S. (1996). Language testing in practice: Designing and developing useful language tests (Vol. 1). Oxford University Press.

Bardovi-Harlig, K., \& Hartford, B. S. (1990). Congruence in native and nonnative conversations: Status balance in the academic advising session. Language learning, 40(4), 467-501.

Bardovi-Harlig, K., \& Griffin, R. (2005). L2 pragmatic awareness: Evidence from the ESL classroom. System, 33(3), 401-415.

Bardovi-Harlig, K., \& Dörnyei, Z. (1998). Do language learners recognize pragmatic violations? Pragmatic versus grammatical awareness in instructed L2 learning. Tesol Quarterly, 32(2), 233-259.

Blum-Kulka, S., House, J., \& Kasper, G. (1989). The CCSARP coding manual.Cross-cultural pragmatics: Requests and apologies, 273-294.

Blum-Kulka, S., \& Olshtain, E. (1986). Too many words: Length of utterance and pragmatic failure. Studies in Second Language Acquisition, 8, 165-179.

Canale, M., \& Swain, M. (1980). Theoretical bases of com-municative approaches to second language teaching and testing. Applied linguistics, 1(1), 1-47.

Hassall, T. (2003). Requests by Australian learners of Indonesian. Journal of Pragmatics, 35(12), 19031928.

Hill, T. (1997). The development of pragmatic competence in an EFL context.

Holtgraves, T. (2008). Conversation, speech acts, and memory. Memory \& cognition, 36(2), 361-374.

Kasper, G., \& Rose, K. R. (1999). Pragmatics and SLA. Annual review of applied linguistics, 19, 81-104.

Kasper, P. D. D. S., Fuger, J., \& Möller, H. J. (1992). Comparative efficacy of antidepressants. Drugs, 43(2), 11-23.

Karkkainen, E. (1992). Modality as a Strategy in Interaction: Epistemic Modality in the Language of Native and Non-Native Speakers of English. Pragmatics and language learning, 3, 197-216.

Olshtain, E., \& Blum-Kulka, S. (1985). Crosscultural pragmatics and the testing of communicative competence. Language testing, 2(1), 16-30.

Scarcella, R. (1979). Watch Up!. Working Papers in Bilingualism, Vol. 19, 79-88.

Searle, J. R. (1975). Indirect speech acts (pp. 59-82).

Taguchi, N. (2002). An application of relevance theory to the analysis of L2 interpretation processes: The comprehension of indirect replies. IRAL, 40(2), 151-176. 
Efeoğlu Şentürk, G. (2017). The effect of L2 English proficiency on request, advice and apology of L1 TurkishL2 English learners. International Journal of Social Sciences and Education Research, 3(1), 297-306.

Taguchi, N. (2005). Comprehending implied meaning in English as a foreign language. The Modern Language Journal, 89(4), 543-562.

Taguchi, N. (2006). Analysis of appropriateness in a speech act of request in L2 English. Pragmatics, 16(4), 513.

Takahashi, S. (1996). Pragmatic transferability. Studies in second language acquisition, 18(02), 189-223.

Takahashi, S. (2005). Noticing in task performance and learning outcomes: A qualitative analysis of instructional effects in interlanguage pragmatics. System, 33(3), 437-461.

Takahashi, S., \& DuFon, M. A. (1989). Cross-Linguistic Influence in Indirectness: The Case of English Directives Performed by Native Japanese Speakers.

Trosborg, A. (1987). Apology strategies in natives/non-natives. Journal of pragmatics, 11(2), 147-167.

\section{Acknowledgements}

The earlier version of this study was presented at 2nd International Conference on Social Sciences and Education Research in Istanbul, on November, 2016. 